\title{
Theresa May Wants to Stop 'Unnecessary Detentions' with New Mental Health Act
}

\author{
Elizabeth Maitland* \\ Recovery Assistance Dogs, Leicester, United Kingdon \\ *Corresponding author: Elizabeth Maitland, Recovery Assistance Dogs, Leicester, United Kingdon

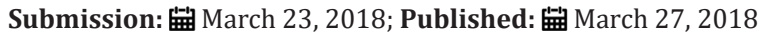

\section{Opinion}

At RECOVERY Assistance Dogs we filled in an Independent Review of the 2007 Mental Health Act by February 28, 2018. The review was about when a person can be admitted, detained, and treated in hospital without their agreement. We made our point that people should have the Human Right to a Fair Trial before they can be locked up against their will. The Law says that only people who are a danger to others or themselves should be detained involuntarily. Yet at the moment people are have to submit to 'unnecessary detentions' for being 'high', unable to answer the question correctly or other reasons that a Court of Law would dismiss.

Theresa May wants to stop 'Unnecessary Detentions' with the New Mental Health Act. This begs the question what does she want to replace it with? Just before the election in June, 2017 she said she would replace "in its entirety the flawed Mental Health Act", which "too often leads to detention, disproportionate effects and the forced treatment of vulnerable people". So now that she is Prime Minister we are watching to see how she is to change an Act made in 1983 that makes us all feel uncomfortable and some of us downright anxious and unsafe as it blurs the line between treatment \& legal proceedings.
The last Mental Health Act in 2007 caused more problems for the Mental Health Survivors fraught with concerns for freedom from force and fear with its contentious Community Treatment Orders. The only improvement was the right for everyone to have a Mental Health Advocate who is sectioned. In the New Act increased provision for funding to improve the availability of Mental Health Advocates should be introduced. The new bill should guarantee that all stays in hospital have some litigation and tribunal or court protection for individuals before they are locked up. Tribunals added on afterwards when it is too late to protect an individual has to stop. As Mark Brown, newspaper Reporter says "The bill could lay out the provisions for those who wished to refuse treatment, and build new models of consent and care."

Many RAD Clients are doing well with their RAD Doggy companions and coping Okay in the Community. They do not need the added discrimination, restrictions and monetary problems of doctors pushing them around and depriving them of their liberty or the company of their best friend. Liz Maitland, Director of RAD is longing for "a new covenant that commits the UK to protecting those that are in Mental Health distress and helping them to get the therapy \& support in the community to nurture and heal".
Creative Commons Attribution 4.0 International License

For possible submissions Click Here Submit Article

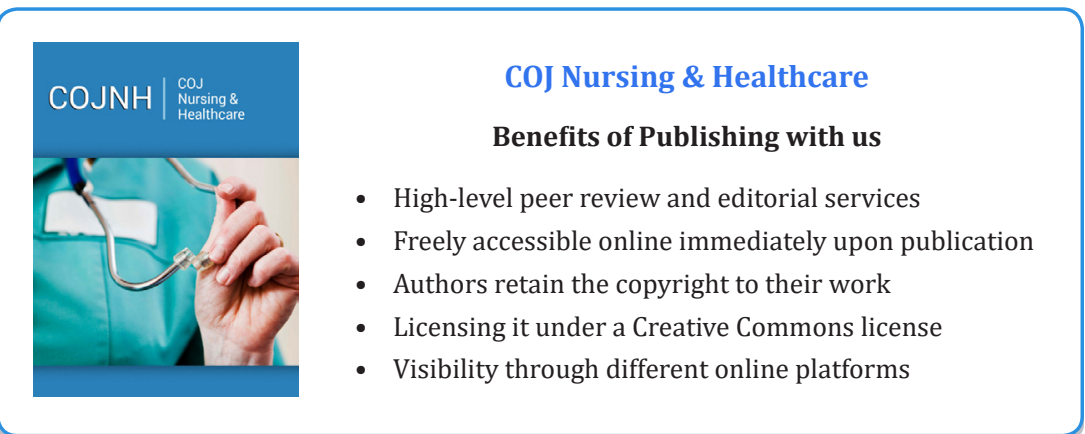

